\title{
Protest as Conservative Phenomenon
}

\author{
Klementin Mile \\ PhD Candidate, European University of Tirana, Albania \\ klementin_mile@yahoo.co.uk
}

\section{Doi:10.5901/ajis.2013.v2n8p154}

\begin{abstract}
One usually takes it for granted that protest is a means to bring changes in the society and, in this sense, all those who protest and demand these changes are positioned as progressives. In contemporary society progressives take on different names Marxian, post-Marxian, environmentalists, libertarians, pacifists etc. Here the issue is not to put in doubt the existence of a better future in protesters' imagination. However, when society has not yet developed certain positions from which it may criticize itself, protest contributes to nothing else but reproducing the society in the same parameters, since it does not change anything structurally. Protest will be analyzed into three meaning dimensions: temporality, facticity, and sociality. This analysis will expose the difference between the societal structure and semantics of protest. This difference is manifested in the temporal dimension as outdated semantics, in the fact dimension as simplified semantics, and in the social dimension as monist semantics.
\end{abstract}

\section{Introduction}

In the democratic regimes of our time protest is considered a form of political participation that indicates a functional democracy, that power holders are controlled by the people, and that the basic constitutional rights of men are observed and have influence in improving governance. In other words, protest represents a value that must be cultivated, as well as a proper form that may bring about positive changes in the society. Taking this for granted, the entire theoretical discussion about protest focuses on the strategies, tactics, organization, aims and motives of protest (Meyer at al, 2002; Della Porta \& Diani, 2006; Tilly, 2007). If a protest fails, the fault is attributed to one or some of these elements. Thereby, all future attempts concentrate on improving the strategy, or tactics and organization, or clearer specification of aims and transparency of motives. But, notwithstanding the lessons learned from previous failures, the history of protests has little in common with success. The pressure of protesting people upon their government has not improved at all the governance quality. The social changes one aimed for have not occurred. The institutions representing the evil and the origin of the problem in the eyes of protesters remain as strong as ever. In these conditions another perspective is required for studying protest: a perspective which does not seek the reasons of failure in the strategy applied and the other abovementioned elements, but in more fundamental factors relating to the very structure of contemporary society. Thus, from this perspective, the questions become: Given that the strategy, tactics, organization, aims and motives of protest are adequate, yet, can protest deliver the social change it promises? And, in the context of contemporary society, how should one reconstruct the concept of protest in order for it to be successful? Through these two questions the debate on protest shifts from the philosophical to the sociological level, and from the futile positioning for or against protest towards a constructive analysis that aims at demonstrating the capacity of this form of political participation and its reconstruction in the framework of contemporary society.

\section{Methodology}

This article follows the principles of radical constructivism. One does not deny the existence of reality, as it is the case with solipsism, but neither can one acquire objective knowledge about the reality through sensual perception, as realists hold. Actually, all knowledge one acquires about the reality is constructed; i.e., one does not have direct and certain access in a single unified reality (von Glasersfeld, 1995; von Foerster, 1984 \& 2003; Maturana \& Varela, 1980 \& 1987; Bateson, 1972 \& 1979). The implications of this thesis for this study relate, first of all, to the special attention one must pay to the way one makes sense of the reality (in this case, to the protest and the society within which it occurs) and specification of the meaning dimensions. Thus, in accordance with the neofunctionalist thesis developed by systems theory, one can analytically distinguish three meaning dimensions: fact dimension, temporal dimension, and social 
dimension (Luhmann, 1995a: 75). Secondly, crucial importance is attached to the description of contemporary society. The scientific quality of explanation and prediction of social events and processes depends on the quality of description of the society. Third, in this study the reality is observed through the binary scheme social differentiation/semantics. Social differentiation refers to the primary differentiation of society, which brings about structural effects on the development of social processes and the very reproduction of society, while semantics refers to the condensed meaning that society articulates for making sense of itself (Luhmann, 1995a; Staeheli, 1998; Andersen, 2003). The distinction between social differentiation and semantics assumes that society may fail the task of adequately understanding itself, i.e. the reality of its structures and processes.

\section{How to describe contemporary society?}

Description of contemporary society relates to the question of its primary differentiation. Amongst all the theories developed for this purpose, more complete and more coherent are Karl Marx's theory of historical materialism and Niklas Luhmann's theory of social systems. These theories have an advantageous position over the rest for they deal with the entire human history, thus making it possible to do comparative analysis. Of course, in addition to them there are other theories, which focus exclusively on the contemporary society such as Ulrich Beck's theory that describes society as 'risk society' (Beck, 1992), Manuel Castells's theory that describes society as 'network society' (Castells, 2010), Lyotard's theory that describes society as 'postmodern society' (Lyotard, 1984), or Debord's society that describes it as a 'society of spectacle' (Debord, 2006). However, besides the fact that these theories do not provide for comparative analysis, they also have another problem. They seem not to refer that much to social differentiation, but almost exclusively to social semantics. In fact, these theories express by way of metaphor the society's attempts to make sense of itself. They contribute to the creation of semantic variation, but they are not helpful for doing analysis focused on the distinction between social differentiation and semantics, since they do not take into account this distinction.

But let us turn for a moment to Marx and Luhmann. According to Marx, human society has passed through several stages: primitive communism, slave society, feudal society, and capitalist society. In addition to these stages, Marx predicted the further evolution of society to socialism and, finally, communism (Marx \& Engels, 2009). Unlike Marx, Luhmann distinguished three types of society during human history: primitive societies, traditional societies, and modern society (Luhmann, 2006: 502-588). What distinguishes one society from another, according to Luhmann, is its form of differentiation. Thus, primitive societies are characterized by segmentary differentiation. This means that the society is differentiated in identical subsystems, in segments, which constitute themselves in the same way and possess the same observational perspective. Such subsystems are for example tribes, villages and families. Unlike primitive societies, traditional societies are differentiated by forming unequal strata, on the basis of hierarchy principle. But, in addition to the up/down distinction, whereby some strata are considered high and other low, traditional societies also use the centre/periphery distinction, e.g. the distinction between the city, as a centre, and the countryside, as a periphery, or the centre of the empire versus other territories under its jurisdiction. Unlike the first two types of society, modern society is characterized by functional differentiation. This means that within it are formed systems that are different from one another with regard to the function they perform for society. Such systems are the political system, the economic system, the legal system, the scientific system and so on.

By using the logic of social differentiation of Luhmann, who distinguishes three principles of differentiation segmentation, stratification, and function - one may notice that in Marx's theory of social evolution there are only two of them: segmentation, in the case of primitive communism, and stratification, in slave society, feudal society and capitalist society. Meanwhile, in communist society, where social classes are supposed not to exist, one can guess that there would be segmentation like in the case of primitive communism, while socialist society may be interpreted as a transition period towards communism and, for that reason, one would find there both stratification and segmentation. The tension between the two theories becomes evident when it comes to the description of contemporary society, which Marx calls capitalist society and Luhmann modern society. While Marx and his followers believe that contemporary society is characterized by hierarchical and centre/periphery differentiation, Luhmann holds that contemporary society is differentiated functionally. In what follows, the analysis of the phenomenon of protest will be developed on the basis of the luhmannian premise that we live in a society, which has been differentiated in functional systems, where, although there are hierarchies and centres, they are not of primary importance. Choosing Luhmann's social theory over that of Marx is done for two reasons: first, this theory is more complex and does not exclude the others; rather, it integrates them in its conceptual framework. Luhmann's theory is able to reformulate and interpret Marx's theory, while the conceptual apparatus of the Marxian theory is inadequate for including Luhmann's social theory. Luhmannian theory, based on 
radical constructivism, can describe Marxian theory as a positivist theory (let us recall the concept of "false consciousness" that assumes the existence of "true consciousness" and the possibility of its identification, or the concept of "alienation", which implies the possibility of a "non-alienated" condition), as a monist theory (the claim that Marxism is not merely an ideology, but also science, i.e. it has monopoly over the truth), or as a theory adequate for traditional societies, but not for modern society (since it gives priority to the economy over all other systems and, therefore, it cannot be verified empirically in the framework of contemporary society). Secondly, Luhmannian theory, unlike Marxian theory, is reflexive: it is simultaneously the theory that describes and explains the social phenomena (the subject) and the theory that is described and explained by itself as merely one of these phenomena (the object). Luhmann is conscious that social theory, although it aims at describing society, is itself part of this society. For this reason, he constructed his social theory in such a way that his theory, after describing the social phenomena of the world, could face itself as object in the field of phenomena and, therefore, confronting a scientific test that it may pass or fail. Thus, Luhmann is in complete coherence with its theoretical premise that there is no privileged position for acquiring knowledge in contemporary society, and less so final knowledge.

\section{Protest as object and concept}

The major part of studies treats protest as object. This is more obvious in the case of empirical and historical studies. In this way, such studies create a confusion of data and facts, but fail to make sense of occurrences. The operative logic of Spencer Brown helps to understand the distinction between object and concept. According to him, to make sense of the world we live in we need distinctions. Thus, by establishing a distinctive boundary, two sides are formed: an internal side and an external side. The observer may mark one, or the other side, or both (although not simultaneously) (Spencer Brown, 1972: 1-4). So, when the observer names one of the sides, while the other remains unspecified, an object is created. When the observer specifies both sides of the distinction, a concept is created. Therefore, as Koselleck maintains, the concept always implies the existence of a counter-concept (2004). The relation between concept and counter-concept is characterized by difference and complementarity. Thus, despite the difference of the two sides of the distinction, the specifications on the one side imply the other. Therefore, if one wants to treat protest as a concept, one needs to specify its other side, which is different, but also complimentary to it. According to Luhmann, protest as a concept can be observed in the distinction between protest and that against which it is protested against: the theme. This is the theme of society that produces, covers, and approves that, which it is protested against (Luhmann, 2003: 337). Only when protest is treated as a concept can one observe the fact of its paradoxical existence. It seems that modern society has developed an autopoietic form in order to observe itself: in society, against society (Luhmann, 2003: 339). Thus protest is positioned against society, creating thereby the illusion that it stands outside society. But, in fact, it can only be society that makes possible everything social, protest included. The negativity of protest is parasitical: it exists because of the positivity of society. Thus, modern society has created the structural conditions that provide for action and reaction, covering and uncovering, construction and deconstruction, conformity and deviance.

The social systems theory developed by Luhmann identifies three types of system: interaction systems, organization systems, and the societal system. Society, as a system, is further differentiated in functional subsystems such as politics, economy, law, science, mass media etc. (Luhmann, 1977). Regarding protest, Luhmann admits that its features do not allow for classifying it into one of the abovementioned subsystems, nor has it developed to the level of taking it for a new kind of social system. For the following analysis, it is important to clearly distinguish protest from other types of social systems: the basic element that reproduces protest is not the presence of actors (interaction), nor decisions (organization), or communication (society). Actually, the main interest and the focus of action of protesters is demonstration (Luhmann, 2003: 336). This feature of protest seems to explain the tendency of protesters to have as much media coverage of their movement as possible. This is so because demonstration, as basic element of protest, must reproduce the conditions of its own continuation: it must be followed by other demonstrations. "Come!" is the key message of protest. This message is expected to have more resonance and to influence more people if transmitted via the mass media. The dark side of this phenomenon is creation of perverted effects. Two of them are worth mentioning: first, making protest dependent on media coverage puts pressure on the movement to produce continuously events, even when there are no conditions for it. Thus, protesters are compelled to thematize and treat as issues to protest against even totally ordinary daily phenomena, by allowing themselves free room for interpretation (or speculation?). As a consequence, they are not taken seriously, do not find the expected resonance from the public, and do not manage to mobilize many people. Secondly, dependence on the mass media creates famous protesters. Empirical observations show that such protesters have the tendency to profit from their fame for improving their own position in the society, 
leaving behind the fate of their movement (Hessdörfer et al, 2010: 12).

\section{Temporality of the semantics of protest}

In the temporal dimension one distinguishes between history and chronology. History begins the moment it is liberated from chronology. Meaning systems have history only to the extent they condition themselves via optional access, be it by focusing on specific past events or through finalizing the future. (Luhmann, 1995a: 79-80). Thus, by referring to the distinction between form of societal differentiation and semantics, one can treat them as systems that have different history, named respectively 'the societal system' and 'the semantic system'. In other words, and because of their different histories, there is no guarantee that semantics will reflect societal changes. Thus, the distinction between societal differentiation and social semantics reveals the semantics of protest as outdated semantics. This semantics is unable to understand the conditionings, the possibilities and the form of modern society.

At the structural level, the semantics of protest corresponds to the differentiation characteristic of traditional societies: stratification and centre/periphery distinction. It is expressed through concepts such as domination, exploitation, manipulation, the evil, omnipotent state (state in the centre or on the top of society), capitalism (reducing the society to the economy, while the economy is only one of society's functional systems), colonization, violence, discrimination on the basis of social status and so on. All these concepts make sense by the counter-concepts positioned above or below them (hence confirming the hierarchy of the society), or otherwise by counter-concepts positioned in the centre or periphery (confirming the other version of traditional society, the centre/periphery differentiation). But the functional differentiation of society brings about other negative phenomena; different from those which constitute the terminology of protest movements. Functional differentiation brings about exclusion, neglect, indifference, high negative integration, ecological problems and depersonalization. This occurs because the functional systems of society in principle accept everyone within their field of operation. These systems operate through symbolically generalized communication media such as money, power, law, truth etc. So, to the extent one has money, one can involve in economic transactions, and to the extent one has power, one can operate in politics. However, what functions symbolically (providing unity), also functions diabolically (causing division). For example, although money provides for inclusion of everyone in the economy, notwithstanding his/her race, ethnicity, faith or age, on the other hand, it excludes from economy all those that have no ability to pay. Thus, turning to a concept for the sake of illustration, an updated semantics of protest would need to focus on exclusion, not exploitation. It is important to understand that exploitation becomes impossible when excluded by the society. One must first be included in order to get exploited. The more contemporary society evolves towards its modernity, the more akin becomes the problem of social exclusion and the less important the problem of exploitation. By not reflecting these societal changes in their semantics, protests either overate the capacity of politics for solving society's problems, or give up before it.

\section{Factuality of the semantics of protest}

The fact dimension refers to meaningful themes and objects and uses the distinction between "this" and "something else". Regarding this meaning dimension it is important to emphasize that factuality and "reality" are not identical. Reality refers to "things", which are constraints on the possibilities of combination in the fact dimension. Thus, the concept of reality hides the fact that for constituting an object there are always two meaning horizons at work - one external and one internal - and, consequently, that one needs twofold description for fixing the meaning of the object (Luhmann, 1995a: 76-77)

In the fact dimension the semantics of protest is very simplistic. It assumes a social reality characterized by unlimited resonance capacity. In addition, it assumes the same resonance capacity for all social systems, thus ignoring their systemic autonomy and their difference from each other in terms of functions, codes and programmes. The semantics of protest is expressed by notions such as reforms, revolution, the system, equality, social justice, or "delayed justice is denied justice". In modern society these notions imply necessarily the operations of more than one social system. For example, the reforms may be initiated by politics, but they will have effects in the economy, education or science, depending on the case. Likewise, the notion of social justice refers to operations occurring simultaneously in at least three different systems: politics, economy and law. In the conditions when each of these systems operates according to its own functional logic, one may reasonably expect asymmetric resonance capacity: an important event in the economy may be totally ignorable in political terms (Luhmann, 1989: 43).

Lack of systemic resonance is observed by the protesters as sign of irresponsibility, lack of integrity, anti-value, 
incapability, corruption, and democratic deficiency. Consequently, protest focuses on "individuals" or special groups, leaving out of attention the functional systems that condition their decisions and actions. Thus, protest is articulated on the normative level (key word: should) and does not reflect at all about the question of possibility or realizing aspirations (key word: could). Naturally, what should be done for improving society and what could be done for it are as different as they are complimentary; but, if the aim of protest is realizing its demands and not creating illusions, the questions of possibility ought to be raised before the questions of normativity. Therefore, the knowledge reservoir of protesters must indispensably include, apart from philosophy and strategic-organisative literature, also social theory and socio-cultural evolution theory.

In abstract terms, the simplification of protest comes because its semantics cannot make the difference between reality and factuality and it refers exclusively to the reality. The consequences of this phenomenon are obvious: in reality everything seems possible, since one finds only one perspective there - that of "the System". If something "possible" does not occur, then the problem is formulated in terms of moral and/or professional performance. Then it is attributed to a part (person, group, institution) of the System. However, it is enough to take into account the difference between reality and factuality in order to understand that the perspective of the System is conditioned and, in this sense, is made possible, by the environment (the other social and psychic systems). Thus, bad governance is not simply a consequence of incapable and corrupted government, but also of the incapable and corrupted opposition, in the context of a public opinion characterized by low sensitiveness and of other social systems functioning in accordance with different autonomous logics.

In order to increase the complexity of protest in modern society one needs to create critique positions, i.e. positions from which the society may criticize itself. These positions can only be created in its functional systems. However, one must distinguish functional systems that operate with a conservative logic from other functional systems characterized by a progressive logic. Thus, conservative logic is to be found in politics (political innovation is very dangerous electorally), in economy (for as long as there are markets and liquidity everything goes well), in the mass media (let's give the public what the public asks for), in law (decision-making on the basis of established principles, concepts and rules). On the other hand, one can find progressive logic and pressure for emancipation in other systems such as art (the imaginary makes it possible for us to observe the real, to put it into perspective and criticize it), religion (the immanence of society becomes an object of observation from a transcendental perspective, although it is constrained by the holy scriptures), science (the criteria of truth are not based on social consensus or the so-called "common sense") and intimacy (the inner experience that is actualized in intimate relations becomes a point of reference for articulating the need for changing social conditions). But when a society has not developed enough its art, religion, science and intimacy, then it finds it almost impossible to criticize itself. Their development means that in the social processes one refers often to these systems, and uses them to reach decisions and to describe himself/herself and others. But, as a matter of fact, how often have we witnessed a preference for artistic logic over that of the mass media, or scientific logic over the economic one, or the religious logic over political logic?

\section{Sociality of the semantics of protest}

The social dimension of meaning articulates the tension between the different perspectives on facts; in other words, the tension between alter and ego. The concepts alter and ego refer both to psychic and social systems. For a sociological analysis of the society alter and ego are taken to be communication partners that do not have absolute control over each other, since it is impossible to predict with certainty the actions of the other. As it were, they are "black boxes" that never become completely transparent. For this reason, although the world we live in is the same for all of us, our realities can be different. Each social and psychic system develops its own special observation and description perspective of the world and, in this sense, there is systemic pluralism par excellence. Unlike primitive and traditional societies, modern society does not have a privileged position from which it may observe and describe itself. In premodern societies this positions was occupied by God (religion) and later on by the sovereign (politics). But the functional differentiation of modern society does not give priority to any of society's functions and, consequently, to any of its functional systems. Thus, a fundamental problem of modern society is that of integration of different perspectives on facts and events, in the conditions of lacking a privileged centre or top for doing this. Postmodern semantics treats this problem, but considers it insolvable and resigns to relativism (Luhmann, 1995b).

In light of the above, the semantics of protest appears monistic. It assumes that there is unity of values, interests and viewpoints, while in fact there is diversity. But one seeks to overcome this diversity through observation schemas inspired by the Marxian thought, e.g. by making the distinction between "false" and "true" consciousness. In other words, 
once the people are freed from the dominating ideology (by falling under another ideology?), they would open their eyes to see "the truth" of their existence in the society, and this truth can only be one and the same for all of them. Consequently, the different positions will transform in a common position, and the different realities will transform in a common reality, and after the consensus mobilization and collective action will follow. Awareness-raising campaigns are prominent formulas for achieving these aims. But the fact that awareness-raising campaign seldom raise awareness must make the protesters reflect. In fact, even this reflection has been made, but with an inadequate focus. Habermas tells us that social emancipation and, by the same token, awareness raising, depends on the way we communicate. According to him, we must create ideal speech situations, where all of us enter as equal, leaving out the public sphere our specific status and instrumental interests, and let the best argument win (Habermas, 1984: 24-28). This solution, which aims at emancipating and sensitizing us, ironically depends on the fact that we are already sensitized. As it were, we must organize a previous effective awareness-raising campaign in order for the current awareness-raising campaign to be effective.

In the social dimension protest legitimizes itself through moral, ethical, or "intellectual" ideas. But morality is only a reduction of sociality, as is reality (according to the viewpoint of a certain intellectual) a reduction of factuality of the world. A specific analysis may reveal clearly how inadequate are these ideas for the protest movement; one can see that this semantics does not take into account the structural conditions of modern society. Morality is not anymore applied in society as its organizing principle (Luhmann, 1993). In modern society morality can only play a supplementary role, but even this role not in unified fashion. This is so because modern society has not only developed systemic codes instead of moral principles (by shifting morality in a secondary position), but it has also created autonomous functioning conditions for these functional systems (therefore, the moral norms of a system cannot be used in another system). Thus, political activity is regulated above all by the considerations of power and the distinction between government and opposition (Luhmann, 1990: 168). Before being judged morally, political action is judged by the criteria of electoral success. The morality in politics finds expression only in cases of corruption, which threaten the very existence of the state, as well as in cases of violation of confidentiality principle (Luhmann, 1994). Both these expressions of morality refer to the political system and its requirements for smooth reproduction, but not to the society at large. Similarly, in science the morality relates only to plagiarism, but is not a criterion for determining the scientific truth of statements, for science has its own theories and methods that provide for it. To give another example, in sport the morality is expressed through the slogan "fair play", but this does not affect the result of the game.

Protests that use ethical ideas are faced with other problems. By understanding ethics as a reflection on morality, or as an academic theory that deals with justification of moral judgments, two problems arise immediately. First, ethics is a theory developed in one of society's systems, the science system; and, in the context of functional differentiation of modern society no system can determine the development of others. Thus, ethical ideas can only "irritate" the functional systems of society, and even that only under specific conditions, when systemic sensitivity (always in accordance with the specific logic of the system in question) is high. Regarding the political system in a democracy, this means that only when public opinion is focused especially on the moral figure of the politician and judges political decision-making on the basis of moral values, only then may politics be irritated by the perception of risk of losing votes and, consequently, react. But also in this case, in the conditions when the distance between the politician and the electorate is considerable (since generally it is only the mass media that raises some communication bridges in-between), the danger of hiding information and deforming the original intentions is always present. Secondly, ethical ideas are too much abstract to be applied directly in concrete decision-making situations. In fact, what has been called "ethics" nowadays is merely a utopia, in the original meaning given to it by Thomas More, i.e. as a paradox of "topos", which is nowhere to be found and does not exist at all (Luhmann, 1993). Thus, although in principle all can agree we ethical ideas, their application brings about divergences, technical impossibilities, interest groups for and against, as well as territorial, cultural and functional conflicts (Kjaer, 2009).

Ideas of the intellectuals suffer from the fact that modern society has no room for the intellectual. Even in the "postmodern" society of Lyotard seems not to have room for them (Lyotard, 1993: 3-7). To participate in society one must have a role (profession), which the society values. The individual qualities are a good premise, but are not enough. They must be translated and adapted to performing a role. If one is intelligent, then one may use this ability in order to become lawyer, economist, politician or teacher. But intellectual is not in the list of professions of modern society. If one, nevertheless, is presented as an intellectual, this only raises doubts about the social identity of that person. Guesses of the kind "How does this person get income? Where does he work? To whom does she serve?" are raised quite naturally, because of the impossibility to act in society, expect from the position of a role. Therefore, modern society a priori delegitimizes the intellectual and the so-called intellectual ideas. 
Protest aims to artificially eliminate social diversity by seeking unity and consensus for its cause. This strategy produces two results: alienation, when achieving consensus, and apathy, when consensus fails. Alienation is brought about by the packing of diversity inside a luminous pack of unity, where diversity cannot stay for long without exploding the pack. The protesters begin to understand that personal aims and interests are not represented properly by the common cause; they begin to understand that the movement has been subjected to serve the personal interests of some people and that all others are being used by them. Thus, the previous and horizontal unity of the protest movement gives way to hierarchical organization, where shares of power and rights are different for different members. In a sense, the new form of movement has very much in common with the organization of institutions it protests against. On the other hand, the apathy that follows the failure to achieve consensus and unity can be interpreted a sign of resignation before social complexity and diversity, and is usually compensated through the development of a semantics of public ignorance. The Sisyphean attempts of protesters reach a culminating point with the exclamation, similar to Jesus at the moment of crossing: "Father, forgive them; for they know not what they do!"

\section{References}

Andersen, Niels Åkerstrøm (2003), Discursive Analytical Strategies. Understanding Foucault, Koselleck, Laclau, Luhmann, The Policy Press.

Bateson, Gregory (1972), Steps to an Ecology of Mind, Jason Aronson Inc.

Bateson, Gregory (1979), Mind and Nature. A Necessary Unity, E. P. Dutton.

Beck, Ulrich (1992), Risk Society. Towards a New Modernity, Sage Publications.

Castells, Manuel (2010), The Rise of the Network Society, Wiley-Blackwell.

Debord, Guy (2006), Society of the Spectacle, Rebel Press.

Della Porta \& Diani (2006), Social Movements. An Introduction, Blackwell Publishing.

Habermas, Jürgen (1984), The Theory of Communicative Action, Vol. 1, Beacon Press.

Hessdörfer, Pabst \& Ullrich (Eds.), (2010), Prevent and Tame. Protest under (Self)Control, Karl Dietz Verlag Berlin.

Kjaer, Poul F. (2009), 'Three-dimensional Conflict of Laws in Europe', ZERP-Diskussionpapier 2.

Luhmann, Niklas (1977), 'Differentiation of Society', The Canadian Journal of Sociology, Vol. 2, No. 1, 29-53.

Luhmann, Niklas (1989), Ecological Communication, Polity Press.

Luhmann, Niklas (1990), Political Theory in the Welfare State, de Gruyter.

Luhmann, Niklas (1993), 'The Code of the Moral', Cardozo Law Review, Vol. 14.

Luhmann, Niklas (1994), 'Politicians, Honesty and the Higher Amorality of Politics', Theory, Culture \& Society, Vol. 11, 25-36.

Luhmann, Niklas (1995a), Social Systems, Stanford University Press.

Luhmann, Niklas (1995b), 'Why Does Society Describe Itself as Postmodern?', Cultural Critique, №. 30.

Luhmann, Niklas (2003), Teoria della società, FrancoAngeli.

Luhmann, Niklas (2006), La sociedad de la sociedad, Herder.

Lyotard, François (1984), The Postmodern Condition: A Report on Knowledge, University of Minnesota Press.

Lyotard, François (1993), Political Writings, UCL Press.

Marx, Karl \& Friedrich Engels (2009), The Communist Manifesto, Echo Library.

Maturana, Humberto \& Francisco Varela (1980), Autopoiesis and Cognition. The Realization of the Living, D. Reidel Publishing Company.

Maturana, Humberto \& Francisco Varela (1987), The Tree of Knowledge. The Biological Roots of Human Understanding, Shambhala Publications, Inc.

Meyer, Whittier \& Robnett (Eds.), (2002), Social Movements. Identity, Culture, and the State, Oxford University Press.

Spencer Brown, George (1972), Laws of Form, The Julian Press Inc. Publishers.

Stäheli, Urs (2003), 'Financial Noises: Inclusion and the Promise of Meaning', Soziale Systeme 9, Heft 2, S. 244-256.

Tilly, Charles (2007), Social Movements, 1768-2004, Paradigm Publishers.

von Foerster, Heinz (1984), Observing Systems, Intersystems Publications.

von Foerster, Heinz (2003), Understanding Understanding, Springer.

von Glasersfeld, Ernst (1995), Radical Constructivism: A Way of Knowing and Learning, RoutledgeFalmer. 